\title{
Developing processes for manufacturing metal aviation technology components using powder bed fusion methods
}

\author{
Anastasia Filatova ${ }^{1, *}$, Tatiana Tarasova ${ }^{1}$, and Pavel Peretyagin ${ }^{1}$ \\ ${ }^{1}$ FGBOU VO "MSTU" STANKIN", 127994 GSP-4 Moscow Vadkovsky lane 1, Russia
}

\begin{abstract}
Favorable parameters for selective melting methods using electron and laser radiation have been established to obtain the required geometric, physical and mechanical characteristics of thin-walled parts for aviation purposes from H18N9T (analogue AISI 321) and Ti6Al4V alloys. Parts were manufactured and field tests were carried out on the stand. It has been shown that the technological processes developed using the SLM and SEBM methods can be recommended for the manufacture of thinwalled parts working in conditions of rapidly changing deformations.
\end{abstract}

\section{Introduction}

Success in the development of aviation depends on a reduction in the mass of aircraft structures [1]. The use of monolithic structures instead of prefabricated ones gives, depending on the type of structures, a savings in weight from 5 to $10 \%$ [2]. The resource of monolithic structures is higher than that for prefabricated ones. Stiffeners, reinforcements, connecting elements and sheathing in a composite structure are made separately and then connected in a monolithic system, where they form an organic whole [3]. The assembly of many parts, which in themselves and as parts of the whole can be well designed, involves a number of sources of defects. The separation of the design into a large number of small individual parts during the design and manufacture adversely affects the weight, cost and accuracy of manufacture, as well as the quality of the outer surface. All this creates the prerequisites for a wider implementation of monolithic structures in the practice of aircraft construction. However, when switching to monolithic structures, it is increasingly necessary to accept a general rise in the cost of their production associated with the technological complications necessary to reduce weight and increase the resource and reliability of structures. When replacing prefabricated structures with a single monolithic part, the question of semi-finished products and methods for manufacturing parts arises in connection with the continuing growth in the size and complexity of such structures.

Recently, methods of selective melting of a metal powder by electron (SEBM) and light beam (laser) (SLM) methods, which belong to the category of Powder Bed Fusion additive manufacturing processes, have become widespread in production [4]. Powder bed fusion is an additive manufacturing process in which thermal energy selectively fuses regions of a

* Corresponding author: anastasia.a.filatova@yandex.com 
powder bed [ISO / ASTM 52900: 2015 (en) [5]]. The processes of electronic and optical radiation differ in technical implementation, but are close to each other in geometric and energy parameters. Therefore, it is advisable to consider the basic physical phenomena for concentrated energy flows from a single "energy" position [6]. Parts obtained by selective melting methods have the following advantages compared to parts manufactured by other methods: the possiblity to obtain complex curved surfaces, internal cavities and protrusions located in different planes, with minimal subsequent machining [7]. This is especially important in the manufacture of parts from difficult materials. For thin monolithic structures obtained by selective melting, high values for the utilization of metal powder have been achieved.

The objective of this work is to establish preferred parameters for selective melting by electron and laser radiation to obtain the required geometric, physical and mechanical characteristics of H18N9T and Ti6Al4V alloys used for the manufacture of protective aircraft air intake lattice modules (Fig. 1a).

\section{Research Methodology}

In this work, the research materials are corrosion-resistant austenitic chromium-nickel steel of H18N9T grade (analogues: AISI 321, EN X6CrNiTi18-10, DIN 1.4541), steel DIN 1.4540 (UNS S15500) and titanium alloy Ti6Al4V (Grade 5). The chemical composition of PRH18N9T is specified in the quality certificate: $\leq 0.1 \% \mathrm{C}, \leq 17.1 \% \mathrm{Cr}, \leq 9.7 \% \mathrm{Ni}, \leq$ $0.68 \% \mathrm{Si}, \leq 0.9 \% \mathrm{Mn}, \leq 0.92 \% \mathrm{Ti}, \leq 0.01 \% \mathrm{~S}, \leq 0.03 \% \mathrm{P}, \leq 0.022 \% \mathrm{H}_{2} \mathrm{O}$. H18N9T steel is used for the manufacture of welded equipment in various industries; pipes, furnace fittings, heat exchangers, muffles, retorts, tailpipes and exhaust manifolds, as well as spark-plug electrodes operating for up to 10,000 hours at a temperature of $800{ }^{\circ} \mathrm{C}$ [GOST 5632 [8]]. The H18N9T steel metal powder (PRH18N9T, fraction from 20 to 63 microns) was manufactured by POLEMA JSC by dispersing molten metal with a stream of compressed gas. The dispersed (granulometric) composition of PRH18N9T and Arcam Titanium Ti6Al4V (Grade 5) (Sweden) was determined to be a fraction of 45 to $100 \mu m$ on an OCCHIO500nano image analyzer (manufactured by OCCHIO SA, Belgium) using image static analysis according to ISO 13322-1. The real-time PRH18N9T particle morphology (Fig. 1b) and Ti6Al4V Arcam Titanium were determined using a scanning electron microscope (VEGA 3 LMH TESCAN, Czech Republic) using scanning electron microscopy according to GOST R 54597 [9; 10].

Selective laser melting of the materials EOS StainlessSteel PH1 (Germany) and PRH18N9T was carried out on an industrial EOS M 280 setup (manufacturer EOS GmbH, Germany) and an experimental setup for SLM (ALAM) with the following technical characteristics: wavelength $-1070 \mathrm{~nm}$, beam divergence $-0,2^{\circ}$, pulse duration and relative intensity - continuous radiation, maximum power - 200 watts. Experiments to determine the influence of the main technological parameters of electron beam melting were carried out on an A2 ARCAM installation (Sweden) [11]. The installation is equipped with an electron beam gun with a tungsten thermionic emission cathode and an accelerating voltage of $U=60 \mathrm{kV}$ with a maximum power of $3500 \mathrm{~W}$ and a working vacuum chamber with a maximum product dimension of $350 \times 350 \times 250 \mathrm{~mm}$. The diameter, depending on the installation capacity, varies continuously within the range of from 200 to 1000 microns. A study of the surface of experimental samples (thin walls), as well as geometric measurements were carried out using a VEGA 3 LMH scanning electron microscope from TESCAN (Czech Republic). The study of microstructures and pole density analysis was performed on a JSM-6610 LV scanning electron microscope form JEOL (Japan) with an attachment for texture analysis. The phase and structural state of the alloys was studied using light, electron scanning and transmission microscopy. The geometric parameters of 
the lattice modules were measured on a multi-sensor coordinate measuring machine for high-precision measurements in the conditions of the Werth SCOPE-CHECK workshop manufactured by Werth Messtechnik (Germany), and roughness measurements were performed on a Hommel Tester T8000 profilograph-profiler manufactured by Hommelwerke Gmbh (Germany). An experimental assessment of block strength by the fatigue vibration test method was determined on a vibrating electrodynamic bench of type V850-440L.

\section{Research results and discussion of the results}

According to the results of granulometric composition tests, the total content of particles that do not correspond to the size of the main fraction corresponds to $20.97 \%$ for PRH18N9T, and $8.71 \%$ for Ti6Al4V Arcam Titanium. The average diameter (arithmetic mean) for PRH18N9T $x_{\mathrm{k}, 0}=52.74 \mu \mathrm{m}$ from the average sample, and for Ti6Al4V Arcam Titanium $x_{\mathrm{k}, 0}=71.54 \mu \mathrm{m}$, was calculated from the data obtained from the samples. It was established that Ti6Al4V Arcam Titanium has a narrow distribution range and a large number of spherical particles, as a result of which high fluidity is achieved, and the roughness parameter of products obtained by selective electron beam melting is reduced. Particles of a spherical shape have a small surface area and are thus easier to apply to the surface of the working zone in selective electron beam melting installations. According to the results of chemical composition tests, PRH18N9T particles have a high degree of homogeneity, which is caused by the fact that, before spraying, the melt was heated until the hereditary structure of the solid state of the alloy components was completely destroyed, and the melt particles dispersed into drops crystallized at high speeds up to tens of thousands of degrees per second. Particles PRH18N9T are characterized by a spherical particle shape, high fluidity, microcrystalline structure, equiaxial type morphology and a small number of satellites.

In order to determine the influence of the SLM process parameters on the structure and properties of the products, experiments were carried out on the manufacture of rollers made of PRH18N9T, varying the laser radiation power, scanning speed, and powder layer thickness. Rollers made of PRH18N9T on the substrate were fabricated with laser radiation power from 80 to $120 \mathrm{~W}$ and scanning speeds from 80 to $180 \mathrm{~mm} / \mathrm{s}$. The thickness of the powder layer that was applied to the substrate was $50 \mu \mathrm{m}$. The length of the roller (melt pool) was $15 \mathrm{~mm}$ for all experiments. For a layer thickness of $50 \mu \mathrm{m}$ and a laser radiation power of $100 \mathrm{~W}$, stable single rollers made of PRH18N9T can be formed at scanning speeds $v_{\mathrm{s}}=80-180 \mathrm{~mm} / \mathrm{s}$ (Fig. 1c). The protective medium was compressed gaseous argon.

To study the physical and mechanical characteristics of the selected preferred modes, samples of various shapes were made. The properties of the samples obtained are shown in table 1.

Table 1. The results of comparative tests of H18N9T steel samples, manufactured using the SLM and traditional method.

\begin{tabular}{|c|c|c|c|c|c|}
\hline \multirow{2}{*}{ NTD* $^{*}$ Condition of Control Samples } & $\sigma_{0,2}$ & $\sigma_{\mathrm{B}}$ & $\delta$ & $d$ \\
\cline { 3 - 6 } & SLM & 576 & 657 & 48 & $\mathrm{~g} / \mathrm{cm}^{3}$ \\
\hline- & Tempering with 1020-1100 ${ }^{\circ} \mathrm{C}$, cooled in water & 196 & 540 & 40 & 7.9 \\
\hline State Std 5949
\end{tabular}

* normative and technical documentation 
To determine the rational parameters of the electron beam treatment of Ti6Al4V Arcam Titanium powder, cubic samples were made whose the model consisted of five thin walls $100 \mu \mathrm{m}$ wide (Fig. 1d, 1e). This thin wall width of the model was chosen in such a way as to ensure its manufacture in one pass of the electron beam. The electron beam power varied from 100 to $400 \mathrm{~W}$, and the displacement velocity was chosen so as to provide an electron beam linear energy communicated by the thin wall from 0.25 to $1.25 \mathrm{~J} / \mathrm{mm}$. As a result of measuring the width of the thin walls obtained, an experimental approximating relationship was constructed between the width of the thin wall and the technological parameters of the process (power and velocity of the electron beam). The width measurement of the thin walls showed a correlation with the diameter of the electron beam in accordance with the linear energy $Q$ used, $[\mathrm{J} / \mathrm{mm}]$. It was found that the width of thin walls increases in direct proportion to an increase in linear energy, while measurements showed that the walls obtained at linear energy of 0.50 and $0.75 \mathrm{~J} / \mathrm{mm}$ have an almost equal width. The most homogeneous microstructure is characterized by samples of products obtained with linear energy $Q=0.75 \mathrm{~J} / \mathrm{mm}$. Therefore, further studies were carried out using this linear energy in an extended power range.

Samples to study the mechanical properties (Table 2) of Ti6Al4V Arcam Titanium alloy powder were made at an Arcam A2 selective electron beam melting facility, when powder layers of about $50 \mu \mathrm{m}$ thickness were successively deposited onto a platform made of corrosion-resistant steel pre-heated to $750{ }^{\circ} \mathrm{C}$. The electron beam velocity varied from 240 $\mathrm{mm} / \mathrm{s}$ to $1200 \mathrm{~mm} / \mathrm{s}$. Preferred modes are selected taking into account the task at hand: minimum wall thickness.

Table 2. Comparative test results for samples from Grade 5 titanium alloy manufactured using SEBM and traditional methods.

\begin{tabular}{|c|c|c|c|}
\hline \multirow{2}{*}{ NTD } & \multirow{2}{*}{ Condition of Control Samples } & $\sigma_{\mathrm{B}}$ & $\delta$ \\
\cline { 3 - 4 } & & $M P a$ & $\%$ \\
\hline- & SEBM & 1008 & 12 \\
\hline Reference [12] & Tempering + aging & 1128 & 8 \\
\hline
\end{tabular}

The ultimate goal of this study was to improve the existing manufacturing technology for protective airplane air intake grilles using additive manufacturing methods. According to the study results of problems in the operation of aircraft, there was a need to reduce the mass of the protective air intake grille with a simultaneous increase in its corrosion resistance. When the jet engine is operating, vortex bundles and small tornadoes appear at the entrance to the air intake, and foreign objects are sucked into the channel from the surface of the flight strip. Foreign objects entering the engine may break it. The air intake protection grill module is the element responsible for protecting the air intake channel from the ingress of foreign objects, and is also an obstacle for air entering the engine. Currently, in the manufacture of protective grid modules from corrosion-resistant H18N10T tape, the main technological process is the formation of reliable, strong and tight joints between frame elements and stiffeners due to contact spot welding and soldering. The modules used are characterized as considerably labor-intensive - cutting, bending, manual assembly of almost seventy parts, welding, soldering, applying metal and nonmetallic coatings with control after each operation is used in their manufacture. In addition, corrosion and soldering fatigue defects are found in operation. To fulfill these requirements (Table 3), the protective grating modules were designed and manufactured from EOS PH1 Stainless Steel and PRH18N9T powders by selective laser melting and from Ti6Al4V Arcam Titanium grade powders by selective electron beam melting (Fig. 1f). A prototype lattice module was made from PH1 EOS Stainless Steel powder to assess the possibility of its manufacture by selective laser melting. Modules of PRH18N9T and Ti6Al4V Arcam Titanium powders passed fatigue vibration tests and tests for resistance to external factors according to State 
Standard RV 20.39.304. To study rapidly changing deformations, the modules were mounted on a bench and exposed to vibrators (pulsators) that reproduced working loads on the modules; strains were recorded using an oscilloscope. The tests were carried out on a vibrating electrodynamic stand and in a salt fog chamber according to State Standard RV 20.57.306. The modules were affixed on the bench table and vibration sensors were attached to them, which exercise control over the loading parameters and the state of the module. The research results showed that the lattice modules are not subject to destruction during aircraft operation. Vibration tests have shown the ability of modules to provide a given strength and durability. After a test cycle in the salt fog chamber, no traces of corrosion damage were detected on the modules. The minimum thickness of the inclined walls of the module frame was $0.3 \mathrm{~mm}$.

Table 3. Results of measuring lattice module geometric parameters.

\begin{tabular}{|c|c|c|c|c|c|}
\hline \multirow{2}{*}{ Element } & \multirow{2}{*}{$\begin{array}{c}\text { Maximum } \\
\text { deviation, in } \mathbf{m m}\end{array}$} & $\begin{array}{c}\text { Deviation from the measured value from the nominal, in mm } \\
\text { welded } \\
\text { H18N10T }\end{array}$ & $\begin{array}{c}\text { SLM EOS } \\
\text { Stainless Steel PH1 }\end{array}$ & $\begin{array}{c}\text { SLM } \\
\text { PRH18N9T }\end{array}$ & $\begin{array}{c}\text { SEBM Arcam } \\
\text { Titanium } \\
\text { Ti6Al4V }\end{array}$ \\
\hline $\begin{array}{c}\text { Slope angle of the } \\
\text { frame element cross } \\
\text { walls }\end{array}$ & $\pm 15^{\prime}$ & -0.53 & $-0.04 ;$ & 0.01 & 0.00 \\
\hline $\begin{array}{c}\text { Regular stiffener } \\
\text { thickness }\end{array}$ & \pm 0.06 & 0.21 & 0.08 & 0.17 & 0.30 \\
\hline $\begin{array}{c}\text { Frame element } \\
\text { thickness }\end{array}$ & \pm 0.06 & 0.15 & -0.15 & 0.16 & 0.21 \\
\hline Stiffener thickness & \pm 0.06 & 0.09 & 0.14 & 0.10 & 0.03 \\
\hline $\begin{array}{c}\text { Enforced wall } \\
\text { thickness }\end{array}$ & \pm 0.06 & -0.01 & 0.11 & 0.12 & 0.06 \\
\hline $\begin{array}{c}\text { Roughness } R a \text {, in } \\
\text { microns }\end{array}$ & $\begin{array}{c}\text { Nominal parameter } \\
6.3\end{array}$ & -1.24 & 11.20 & 6.18 & 22.13 \\
\hline
\end{tabular}

\section{Conclusions and Recommendations}

Arcam Titanium Ti6Al4V and PRH18N9T powder materials were selected and studied. Preferential SLM regimes were determined for the material PRH18N9T and the relationships between SLM parameters, structure, and the physical and mechanical properties of the samples were determined.

The selective electron beam melting method is considered to be the most promising for the additive production of products from titanium and its alloys in aircraft manufacturing. The effects of the main technological parameters for thin wall width were determined using the selective electron beam melting method. Differences in the microstructure and surface of the experimental samples of the products obtained were determined at different linear beam energies. The optimal linear energy of the beam was found. We consider it to be advisable to conduct further research in an extended power range.

Based on test results, both protective grill modules can be used in the manufacture of aircraft. The transition of the protective air intake grille module from an assembled unit to a monolithic part, while replacing the steel alloy with titanium, provides the following advantages:

1. Weight reduction while maintaining necessary strength and resistance to highfrequency fluctuations;

2. High corrosion resistance in a marine environment;

3. A reduction in the complexity of manufacturing due to the lack of soldering, welding, fitting and assembly work and subsequent straightening;

4. All parts are exactly the same, which ensures interchangeability. 
It has been shown that the technological processes developed can be recommended for the manufacture of modules operating under rapidly changing deformations. The results and recommendations can be implemented by replacing traditional methods and materials for the manufacture of protective air intake grille modules in aircraft.

This work was financed by the Ministry of Education and Science of the Russian Federation within the framework of the State Assignment \#11.1267.2017/4.6.

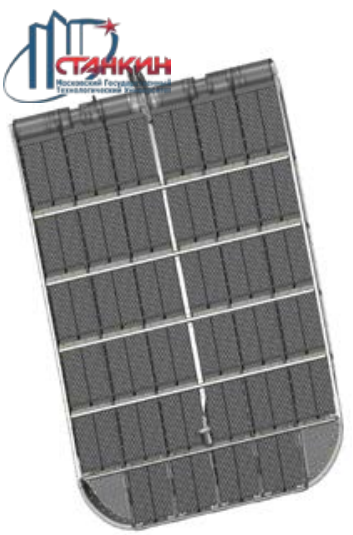

a

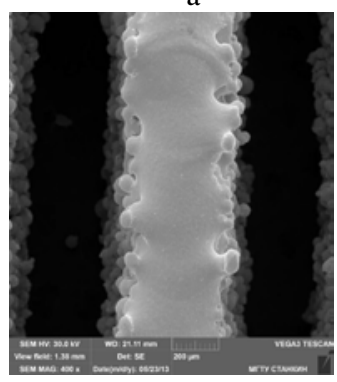

d
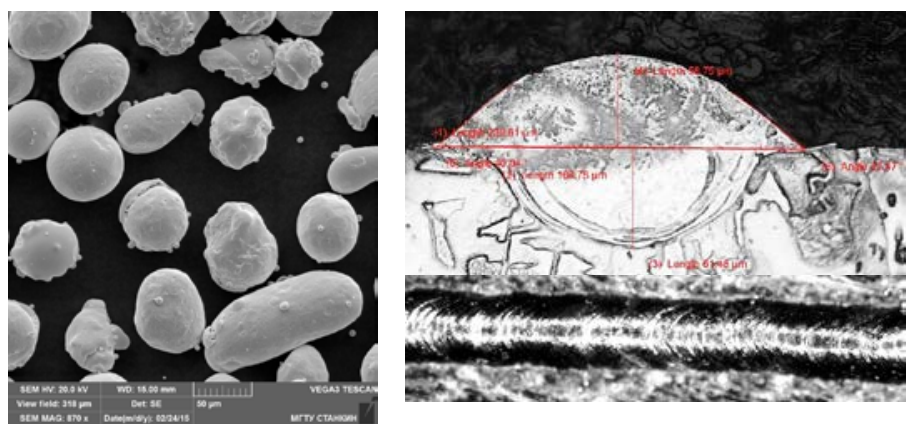

b

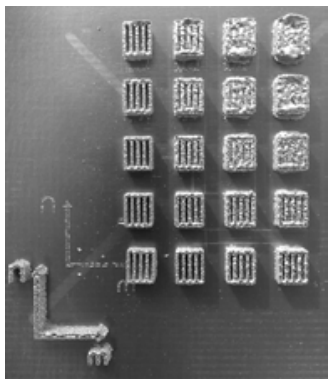

$\mathrm{e}$

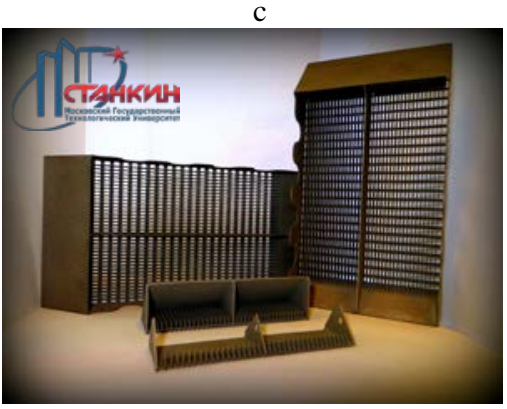

$\mathrm{f}$

Fig. 1. a - Protective grille with cells for installing modules; b - Microstructure surface of the PRH18N9T particles, magnification: $870 \times$; c - Geometrical characteristics of a single roller PRH18N9T in the cut (top) and top (bottom) of the fused layer, magnification: 20 and $5 \times$; d - SEM image of the experimental sample surface - thin walls obtained with the linear energy $Q=0.75 \mathrm{~J}$ / $\mathrm{mm}$; e - Experimental samples of products made with various technological parameters, according to the experimental plan at a preheating temperature $T_{0}=750{ }^{\circ} \mathrm{C}$; $\mathrm{f}$ - Modules and their fragments made by SLM \& SEBM methods.

\section{References}

1. Tarasova, T. V., et al. Technical Problems and Perspectives of Implementing the Selective Laser Melting Method for Producing Structural Components for Aircraft. Materials Science Forum, 834, 29-33 (2015)

2. Vigdorchik, S. A. Tekhnologicheskie osnovy proektirovaniya i konstruirovaniya samoletov (konspekt lekcij). CHast' II. Rotaprint MAI, 130 (1975)

3. Hertel', G. Tonkostennye konstrukcii. Elektronnaya versiya. KyuKdeKaM, 528 (2012)

4. Grigor'ev, S. N., Smurov, I. YU. Perspektivy razvitiya innovacionnogo additivnogo proizvodstva $v$ Rossii i za rubezhom. Innovacii, 10 (180), 76-82 (2013) 
5. ISO / ASTM52900-15, Standard Terminology for Additive Manufacturing - General Principles - Terminology, ASTM International, West Conshohocken, PA, (2015)

6. Rykalin, N. N., Uglov, A. A., Zuev, I. V., Kokora, A. N. Lazernaya i elektronnoluchevaya obrabotka materialov. Mashinostroenie, 495 (1985)

7. Grigor'ev, S. N., Tarasova, T. V. Possibilities of the Technology of Additive Production for Making Complex-Shape Parts and Depositing Functional Coatings from Metallic Powders. Met Sci Heat Treat, 57, 579 (2016)

8. GOST 5632—2014 Nerzhaveyushchie stali i splavy korrozionno-stojkie, zharostojkie i zharoprochnye. Marki (s Izmeneniem N 1)

9. Nowotny, Steffen, et al. Methods for Characterizing Properties of Corrosion-Resistant Steel Powders Used for Powder Bed Fusion Processes. Materials Science Forum, 876, 1-7 (2016)

10. Filatova , A., Tarasova, T. Testing and Introduction of Medical Products Manufactured by Selective Melting. Materials Today: Proceedings, 11, (1), 300-304 (2019)

11. Peretyagin, P. Y., et al. Main Technological Parameters Influence of Selective Electron Beam Melting on Properties of Thin-Walled Titanium Alloy Samples. Materials Science Forum, 834, 13-20 (2015)

12. Tumanov, A.T. Aviacionnye materialy. Mashinostroenie (1966) 